\title{
HTLV-2 infection still prevalent among older injecting drug users in Stockholm, Sweden - indications of limited spread to the younger generation
}

\author{
Kerstin Malm ${ }^{1 *}$, Kristina Hillgren ${ }^{2}$, Sven Britton ${ }^{3}$, Sören Andersson ${ }^{1 *}$ \\ From 15th International Conference on Human Retroviruses: HTLV and Related Viruses \\ Leuven and Gembloux, Belgium. 5-8 June 2011
}

\section{Background}

High prevalence rates of HTLV-2 have been found among injecting drug users (IDU) in several European countries. In studies in early 1990 s among IDUs in Stockholm, HTLV-2 prevalence rates of $2.3 \%$ and $3.2 \%$ were found, while HTLV-1 was rare (1-2). We have now, in 2007-8, performed a new study in a similar population in Stockholm, Sweden.

\section{Objectives}

To study if HTLV-2 is still prevalent among IDUs in Stockholm. If so, to see if epidemiological characteristics and risk factors are similar as in 1994.

\section{Methods}

Serum samples from IDUs in Stockholm, during the years 2007-8 $(\mathrm{N}=1079)$ were collected and investigated for HTLV-1/2 antibodies. Data regarding age, sex, current drug use, country of origin, detention and homelessness were collected.

\section{Results}

Among 1079 investigated subjects, 35 were found to be positive for antibodies to HTLV-1 and/or HTLV-2, giving an overall HTLV-prevalence of $3.2 \%$. Of these, 2 (0.2\%) had antibodies to HTLV-1, 28 to HTLV-2 (2.6\%) and $5(0.5 \%)$ had non-typeable antibodies to HTLV. The overall study group had similar age and sex distribution as in 1995. However, the HTLV-positive individuals were 10 years older than the HTLV-negative group (mean age) and compared to the cases studied in 1995.

\section{Conclusion}

The HTLV prevalence among IVDUs in Stockholm, Sweden, 2007-8 was comparable to the rates found in the early 1990s. As back then, the HTLV-positive IVDUs were significantly older than the HTLV-negative persons. However, in the present study the age difference was more pronounced, 10 years vs 4 years mean difference. The higher age of HTLV cases indicates either a spread of HTLV mainly among older individuals, little spread to the younger persons or possibly limited spread of HTLV in general, since the HTLVinfected cases are now more than 10 years older than in 1995.

\section{Author details}

${ }^{1}$ Department of Laboratory Medicine, Örebro University Hospital, Örebro, Sweden. ${ }^{2}$ Maria Beroendecentrum, Centre for Dependency Disorders, Stockholm, Sweden. ${ }^{3}$ Clinic of Infectious Diseases, Karolinska University Hospital, Solna, Sweden.

Published: 6 June 2011

doi:10.1186/1742-4690-8-S1-A67

Cite this article as: Malm et al.: HTLV-2 infection still prevalent among older injecting drug users in Stockholm, Sweden - indications of limited spread to the younger generation. Retrovirology 2011 8(Suppl 1): A67

\footnotetext{
* Correspondence: soren.andersson@orebroll.se

'Department of Laboratory Medicine, Örebro University Hospital, Örebro,

Sweden

Full list of author information is available at the end of the article
}

(c) 2011 Malm et al; licensee BioMed Central Ltd. This is an open access article distributed under the terms of the Creative Commons 